\title{
ELETROFORESE CAPILAR ACOPLADA À ESPECTROMETRIA DE MASSAS (CE-MS): VINTE ANOS DE DESENVOLVIMENTO
}

\author{
Nilson Antonio Assunção e Etelvino José Henriques Bechara \\ Departamento de Bioquímica, Instituto de Química, Universidade de São Paulo, CP 26077, 05513-970 São Paulo - SP, Brasil \\ Ana Valéria Colnaghi Simionato*\# e Marina Franco Maggi Tavares \\ Departamento de Química Fundamental, Instituto de Química, Universidade de São Paulo, CP 26077, 05513-970 São Paulo - SP, \\ Brasil \\ Emanuel Carrilho \\ Departamento de Química e Física Molecular, Instituto de Química de São Carlos, Universidade de São Paulo, CP 780, 13560-970 \\ São Carlos - SP, Brasil
}

Recebido em 29/1/08; aceito em 7/5/08; publicado na web em 8/10/08

\begin{abstract}
CAPILLARY ELECTROPHORESIS COUPLED TO MASS SPECTROMETRY (CE-MS): TWENTY YEARS OF DEVELOPMENT. CE-MS has been increasingly used for analysis of a vast array of compounds. This article reviews the different electrophoretic modes, interfaces and mass analyzers that are commonly used in the CE-MS coupling, as well as the technique advantages and performance characteristics. A large compilation of CE-MS applications is also presented. Therefore, this review is both a guide for beginners and a collection of key references for people who are familiar to the technique. Furthermore, this is the first CE-MS review published in a Brazilian journal and marks the installation of the first two commercial CE-MS units in Sao Paulo State.
\end{abstract}

Keywords: capillary electrophoresis; electrospray ionization; mass spectrometry.

\section{INTRODUÇÃO}

A eletroforese capilar (CE) vem ocupando um espaço crescente na química analítica como uma poderosa ferramenta de separação e identificação de uma ampla gama de moléculas. A CE possui alta resolução e eficiência, parâmetros estes de grande importância em um processo de separação. Outra vantagem é o baixo custo operacional: mesmo em condições em que se empregam solventes orgânicos, os volumes consumidos de amostra e eletrólito são desprezíveis comparados à cromatografia líquida de alta eficiência (HPLC), até mesmo quando a última é utilizada em escala capilar. Ressaltamos também que os processos eletroforéticos têm como característica positiva a pequena quantidade de amostra injetada (ordem de $\mathrm{nL}$ ), fator de importância em aplicações clínicas. Porém a maior contribuição que a CE oferece é sua complementaridade aos métodos já estabelecidos, devido à variedade de modos de separação existentes - e muitos ainda em desenvolvimento - os quais permitem a análise de praticamente todas as classes de compostos. ${ }^{1-3} \mathrm{~A} \mathrm{CE}$ acoplada à espectrometria de massas (CE-MS) surgiu, aproximadamente, há duas décadas, e foi e vem sendo usada em diferentes aplicações, com crescente aceitação. O sucesso desta combinação alia o alto poder de resolução e eficiência da CE com a universalidade e sensibilidade que a MS oferece frente a outros sistemas de detecção como, por exemplo, espectrofotometria na região do UV-visível, bem como fluorescência induzida a laser (LIF - laser induced fluorescence), que são pouco informativos em relação à estrutura do analito. Um exemplo de tais características de MS envolve seu uso juntamente a ferramentas computacionais, o que é altamente recomendado em estudos envolvendo amostras complexas (como proteínas, peptídeos e metabólitos), já que informações como massa molecular e estrutura (MS em tandem) são indispensáveis para

*e-mail: avsimionato@iqm.unicamp.br

\#Endereço atual: Departamento de Química Analítica, Instituto de Química, Universidade de Campinas, CP 6154, 13083-970 Campinas - SP, Brasil caracterização e quantificação de tais analitos.

Desta forma, as informações oferecidas pela segunda dimensão do detector de massas constituem uma outra vantagem do uso de CE-MS. Assim, solutos que apresentam pequenas variações no tempo de migração, ou até mesmo que migram com a mesma velocidade, podem ser identificados. Neste cenário, a CE-MS vem emergindo como uma ferramenta de grande impacto em bioanalítica, porém ainda são necessários grandes investimentos em pesquisa e desenvolvimento para atingir sua plena capacidade tecnológica..$^{4-7}$

\section{INSTRUMENTAÇÃO}

Em 1987, Olivares et al. relataram o uso inédito do espectrômetro de massas como detector para CE. ${ }^{8}$ Desde então, a técnica CE-MS tem recebido crescente aceitação, onde o MS complementa, ou substitui, detectores convencionais que são menos informativos e universais. ${ }^{9,10}$

$\mathrm{O}$ acoplamento off-line CE-MS usando dessorção em plasma e ionização e dessorção a laser assistida por matriz (MALDI - matrixassisted laser desorption ionization) como fontes de ionização também já foram relatados. ${ }^{11-15}$ Porém, os sistemas CE-MS realmente efetivos foram os de acoplamento on-line, inicialmente usando ionização por bombardeamento com átomos rápidos em fluxo contínuo (cf-FAB - continuous-flow fast atom bombardment) com interfaces do tipo junção líquida (liquid junction) ${ }^{16-18}$ e com líquido auxiliar (sheath liquid). ${ }^{19-21}$ No entanto, o sistema CE-MS on-line somente tornou-se viável e robusto quando uma fonte electrospray (ESI - electrospray ionization) foi empregada. ${ }^{8}$ Um diagrama universal do sistema CE-MS é apresentado na Figura 1, mostrando de maneira esquemática todos os compartimentos dos sistemas CE e MS. Também, de maneira geral, são ilustradas na Figura 1 algumas possibilidades para acoplamento CE-MS cobrindo os modos de separação eletroforética, modos de ionização e diferentes interfaces, e os analisadores de massas.

Entre os vários modos de separação existentes em CE, os usados 


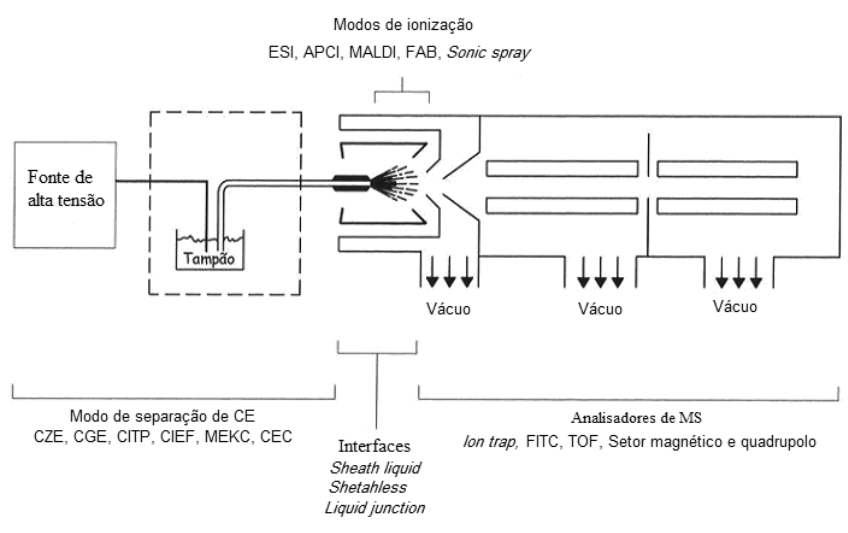

Figura 1. Diagrama de um sistema CE-ESI-MS. CZE: capillary zone electrophoresis; CGE; capillary gel electrophoresis; CITP: capillary isotachophoresis; CIEF: capillary isoelectric focusing; MEKC: micellar electrokinetic chromatography; CEC: capillary electrochromatography. ESI: electrospray ionization; APCI: atmospheric pressure chemical ionization; MALDI: matrix assisted laser desorption ionization; FAB: fast atom bombardment. FTICR: Fourier transform ion cyclotron resonance; TOF: time of flight

no sistema CE-MS devem apresentar características específicas, principalmente quanto à volatilidade dos componentes do eletrólito. Modos de separação como eletroforese capilar de zona (CZE - capillary zone electrophoresis) com tampões voláteis ou não-aquosos são amplamente usados em CE-MS ${ }^{22}$ e eletrocromatografia capilar (CEC - capillary electrochromatography). ${ }^{23,24}$ Os trabalhos pioneiros envolvendo aplicações de CE-MS, utilizando eletrólitos não-aquosos, foram realizados por Tomlinson et al..$^{25}$ na separação de drogas e metabólitos. Uma das vantagens que estes tipos de eletrólitos oferecem é a formação de um spray estável e compatível com o sistema MS. ${ }^{26,27}$ Este fenômeno ocorre principalmente ao se utilizar capilares com revestimento polimérico interno e eletrólitos contendo modificadores orgânicos (como formamida, metanol e acetonitrila), em análises de proteínas e peptídeos. ${ }^{28-30}$

Outros modos de separação que empregam eletrólitos mais elaborados, como isotacoforese capilar transiente ( $t$-CITP - transient capillary isotacophoresis), focalização isoelétrica capilar (CIEF capillary isoeletric focusing) e cromatografia eletrocinética micelar (MEKC - micellar electrokinetic chromatography), também podem ser utilizados..$^{31-34}$ Nestes casos, para evitar a contaminação do detector pelos componentes não voláteis do eletrólito (tensoativos, ciclodextrinas, etc), uma alternativa de acoplamento denominada preenchimento parcial ( $\mathrm{PF}$ - partial filling) foi proposta. ${ }^{35} \mathrm{Em} \mathrm{PF}-$ MEKC, por exemplo, o capilar é primeiramente preenchido com o eletrólito apropriado para o acoplamento com MS (volátil), seguido pela introdução do eletrólito micelar e, finalmente, pela injeção da amostra. Os analitos se separam no eletrólito micelar de acordo com suas hidrofobicidades e, então, migram para o eletrólito volátil, livre de tensoativo, seguindo em velocidade constante até o detector. A corrente é interrompida antes que o eletrólito micelar alcance o detector, evitando assim a contaminação deste. ${ }^{36,37}$

A combinação de MEKC com ESI-MS foi demonstrada com sucesso na análise de compostos quirais por Shamsi et al.. ${ }^{38} \mathrm{O}$ polisódio $\mathrm{N}$-undecanoil-L-valinato foi empregado como tensoativo por ser compatível com MS. O uso deste sistema micelar demonstrou-se vantajoso uma vez que o tensoativo polimérico auxiliou no processo de ionização, levando a uma alta relação sinal/ruído, comparada a sistemas monoméricos (Figura 2). Frente a esse cenário, analitos quirais polares (carregados ou neutros) podem ser separados e detectados por MEKC-MS com alta eficiência, seletividade e sensibilidade.
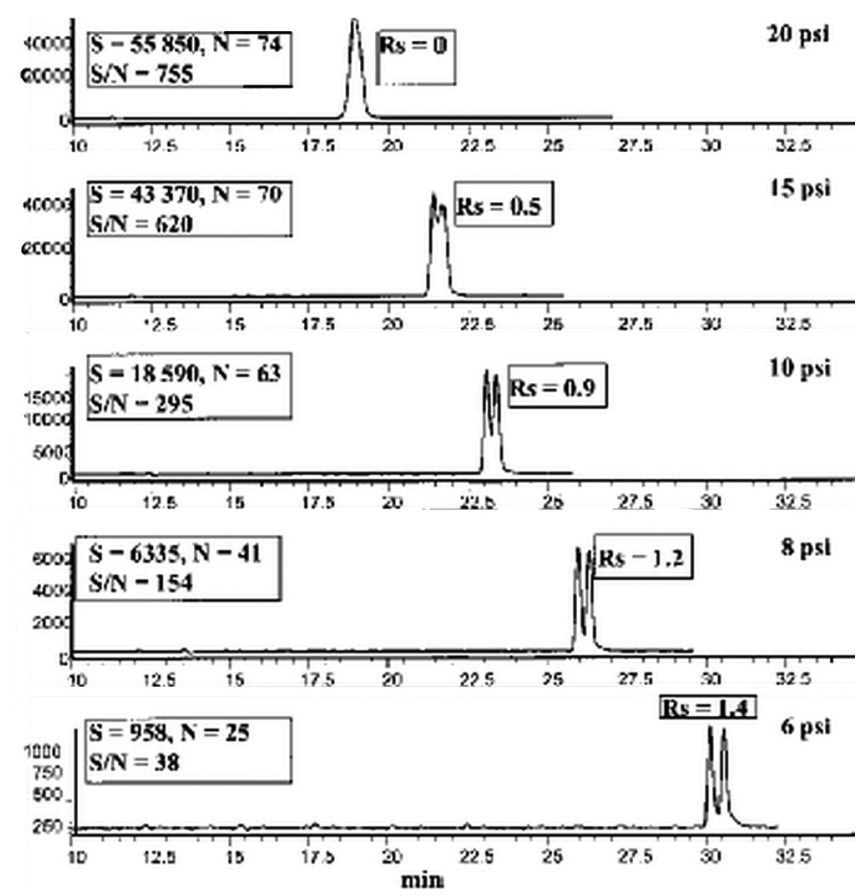

Figura 2. Separação da mistura racêmica dos compostos: terbutalina, clenbuterol, salbutamol, 3-aminopirrolidina, ibuprofenol (IB), 2-hidroxiibuprofenol, carboxiprofenol e vacomicina por MEKC-ESI-MS, demonstrando o efeito da variação da pressão do gás nebulizador sobre a resolução. Reproduzida da ref. 38 com permissão da Wiley-VCH Verlag GmbH \& Co. KGaA

O uso de microdispositivos (microchips) de separação eletroforética com detecção por espectrometria de massas ( $\mu$ CE-MS) também vem crescendo. ${ }^{39-46}$ Com este propósito, diferentes configurações de interfaces já foram desenvolvidas, tal como acoplamento em linha com MALDI-MS..$^{47-49} \mathrm{Jin}$ et al..$^{50}$ apresentaram um trabalho revolucionário construindo um sistema de reator enzimático em linha no qual a bomba seringa, tradicionalmente usada para gerar o fluxo hidrodinâmico, foi substituída pelo fluxo eletroosmótico, levando as proteínas até o reator enzimático. As enzimas foram imobilizadas em uma fase estacionária e neste sistema foi possível, em uma única etapa, promover a digestão de proteínas em 12 min com um sistema integrado de eletroforese na forma de um chip e sua caracterização em um sistema MALDI-TOF-TOF (time of flight).

O acoplamento em linha usando extração em fase sólida - eletroforese capilar - ionização por electrospray - espectrometria de massas por tempo de vôo (SPE- $\mu$ CE-ESI-TOF-MS) também já foi desenvolvido. ${ }^{51}$ Para isso, o microchip foi fabricado em poli(dimetilsiloxano) usando fios de aço como molde, que definiram canais cilíndricos de $50 \mu \mathrm{m}$ de diâmetro. Capilares de sílica fundida foram inseridos nesta estrutura. O microchip foi então separado em dois níveis: no nível inferior o canal foi preenchido com poliestireno para realizar a extração e no nível superior ocorreu a separação eletroforética, que terminou em uma interface de electrospray sem líquido auxiliar.

\section{Configurações para a interface CE-MS}

A liberação de íons provenientes de gotículas à pressão atmosférica, na região da fonte de íons para o vácuo do analisador de massas, é um processo comum a ambas as técnicas de cromatografia líquida (LC) e CE. Desta forma, as interfaces para o acoplamento CE-MS foram desenvolvidas com base nas de LC-MS já existentes. ${ }^{31}$ Contudo, em CE-MS, o circuito elétrico envolvido na separação eletroforética (que deve ser fechado na saída do capilar, ou entrada do espectrômetro 
de massas), a baixa velocidade do fluxo eletrosmótico e a natureza do eletrólito de separação devem ser considerados.

As três configurações comumente utilizadas para o acoplamento entre CE e ESI-MS são: com líquido auxiliar coaxial (coaxial sheath liquid), com junção líquida (liquid junction) e, sem líquido auxiliar (sheathless ou nanospray). Todas as configurações envolvem o fechamento do circuito de alta tensão na extremidade de saída do capilar de separação. Estas configurações diferem umas das outras pela posição dos eletrodos e a natureza do ambiente de ionização (presença de líquido auxiliar ou não), para a formação do spray na entrada do sistema ESI-MS, e serão melhor discutidas individualmente. ${ }^{33}$

\section{Interface com líquido auxiliar coaxial (coaxial sheath liquid)}

A interface com líquido auxiliar coaxial é a modalidade mais usada para o acoplamento CE-ESI-MS devido à sua fácil construção, estabilidade e reprodutibilidade. O líquido auxiliar é introduzido através de um tubo de aço inoxidável concêntrico ao capilar eletroforético, em vazões que variam de nanolitros a poucos microlitros por minuto. A mistura entre o efluente eletroforético e o líquido auxiliar ocorre na extremidade do tubo. Um gás nebulizador - que auxilia na formação do spray - pode ser introduzido através de um terceiro tubo concêntrico externo (Figura 3). O circuito eletroforético pode ser fechado pelo aterramento do capilar metálico (agulha) do ESI. A estabilidade e a simplicidade de implementação desta interface constituem algumas vantagens deste acoplamento. Por outro lado, a principal desvantagem desta técnica é a perda de detectabilidade devido à diluição dos analitos ao se misturarem com o líquido auxiliar, levando a limites de detecção maiores que os observados na ausência deste (interface sheathless). Porém, a otimização de parâmetros eletroforéticos (como pH, concentração e natureza do tampão) e do modo de ionização (natureza e concentração de solvente orgânico e aditivos, e vazão do líquido auxiliar) podem melhorar a sensibilidade para uso geral desta interface. ${ }^{34}$

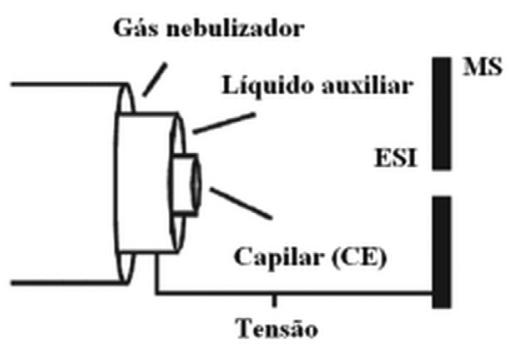

Figura 3. Interface CE-ESI-MS com líquido auxiliar coaxial

Apesar desta configuração oferecer flexibilidade na escolha do tampão eletroforético, os tampões comumente usados em CE - como fosfato e borato - podem gerar problemas na interface ESI devido à baixa volatilidade, podendo contaminá-la e suprimir a ionização dos analitos, gerando espectros de massas pouco informativos. Essa limitação deve ser especialmente considerada quando CE é empregada em diferentes modalidades (MEKC e CGE, por exemplo) nas quais aditivos não compatíveis com ESI-MS são adicionados ao eletrólito. Assim, tampões orgânicos, como ácido fórmico e acetato ou bicarbonato de amônio, são os mais usados em CE-ESI-MS.

Um avanço no desenho da interface ESI com líquido coaxial para o formato ortogonal, isto é, a $90^{\circ}$ com relação ao eixo do espectrômetro, ${ }^{52}$ ou para o formato excêntrico, isto é, alinhado com o eixo do espectrômetro ${ }^{53}$ porém não centralizado, introduziu uma maior flexibilidade na escolha dos eletrólitos da CE. O uso de uma interface ortogonal à entrada da amostra (contra-eletrodo) no MS reduz o risco de contaminação ou obstrução da entrada do MS e permite o uso de tampões eletroforéticos moderadamente não voláteis, podendo melhorar a separação dos analitos. ${ }^{54}$ Nesta interface, a agulha do ESI é aterrada e uma alta tensão é aplicada na entrada do MS, para onde os íons são direcionados devido à interação eletrostática. Assim, a probabilidade de apenas moléculas carregadas entrarem no MS é maior do que em interfaces lineares, aumentando a detectabilidade das interfaces ortogonais. Por essas razões, a interface ESI ortogonal é a mais usada e comercializada para o acoplamento CE-ESI-MS (Figura 4).

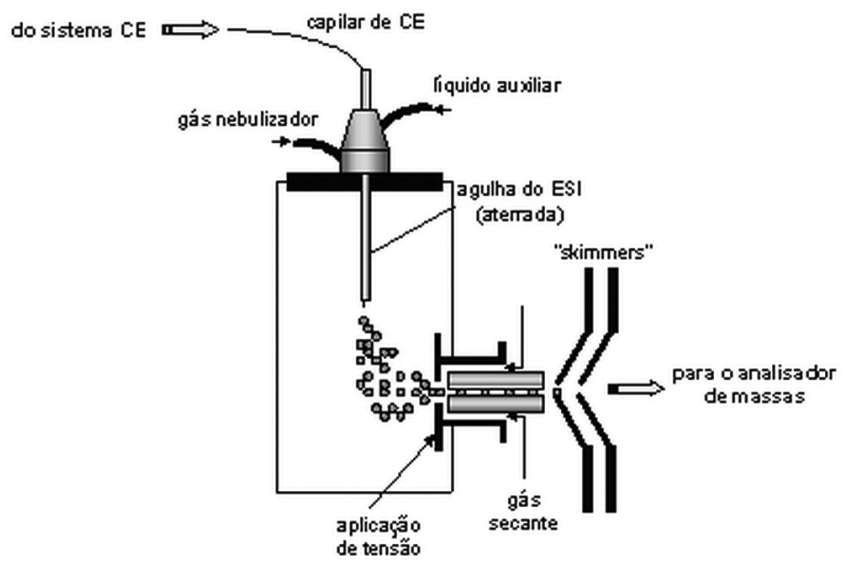

Figura 4. Interface CE-ESI-MS com líquido auxiliar ortogonal

\section{Interface sem líquido auxiliar (sheathless)}

Na Figura 5 é apresentado um diagrama da interface sem líquido auxiliar. Esta interface é, conceitualmente, a mais simples e a mais adequada porém, experimentalmente, é a mais difícil para o acoplamento CE-ESI-MS. A maior dificuldade experimental é manter simultaneamente os circuitos elétricos de CE e ESI. Para isso, é necessária a deposição de um filme fino de material condutor (como ouro, prata, polímero condutor ou grafite) na extremidade do capilar. ${ }^{34}$ A estabilidade do spray é auxiliada pelo formato da extremidade de saída do capilar, a qual é normalmente pontiaguda (cônica) a fim de auxiliar a formação do spray. Uma alternativa é inserir a ponta do capilar dentro de uma agulha de metal, a qual auxilia na estabilidade do contato elétrico dos dois sistemas.

Algumas das limitações da interface sheathless são: o tempo curto de vida; a montagem delicada da interface; a necessidade de recobrimentos de ótima qualidade para o funcionamento adequado do ESI e, a formação de espécies químicas em decorrência de reações eletroquímicas nesta superfície e conseqüente detecção pelo MS.

Nesta interface, a tensão é aplicada diretamente na extremidade de saída do capilar através do material condutor depositado em sua extremidade afunilada. Os limites de detecção atingidos com essa

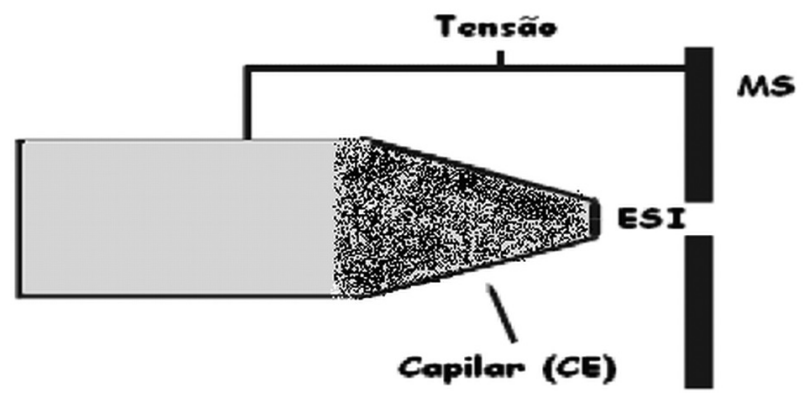

Figura 5. Interface CE-ESI-MS sem líquido auxiliar. A parte escura na ponta do capilar representa o filme metálico depositado 
técnica são os mais baixos dentre as interfaces disponíveis, porque não ocorre diluição do efluente eletroforético com o líquido auxiliar. Porém, a instabilidade da interface e a limitação na escolha do tampão eletroforético (que deve ser volátil já que entrará diretamente no espectrômetro de massas) são também desvantagens que limitam o uso desta técnica. Por essas razões, a literatura apresenta apenas $11 \%$ de trabalhos onde este tipo de interface é usado para o acoplamento CE-ESI-MS. ${ }^{10}$

\section{Interface com junção líquida (liquid junction)}

Na Figura 6 é apresentado um diagrama da interface CE-ESI-MS com junção líquida. Nesta configuração, um eletrodo é inserido na extremidade próxima à entrada do MS pela junção do capilar com outro capilar e o ponto onde o sistema é aterrado. O capilar eletroforético termina em um reservatório contendo um líquido auxiliar, usado para fechar o circuito eletroforético, e este é alinhado com a agulha do electrospray, posicionada do lado oposto do reservatório. O contato elétrico para fechar o circuito é estabelecido através do líquido auxiliar. Uma configuração alternativa é o uso de uma união em " $T$ " para conectar o capilar, a agulha de ESI e o reservatório. A distância entre o capilar e a agulha de ESI é de cerca de 10 - 25 $\mu \mathrm{m}$ para que ocorra a transferência efetiva dos analitos durante a formação do spray. A principal vantagem deste tipo de acoplamento é que CE e ESI podem ser operados independentemente. Assim, diferentemente das interfaces sem líquido auxiliar com deposição de material condutor sobre a própria ponta do capilar, problemas que porventura ocorram na agulha de ESI podem ser resolvidos facilmente pela sua troca, sem afetar o capilar de CE e vice-versa. Além disso, esta interface oferece flexibilidade para a escolha do eletrólito de separação. Por outro lado, algumas desvantagens deste sistema são: o posicionamento crítico do capilar; formação de bolhas na superfície no eletrodo devido a reações eletroquímicas (eletrólise) resultando em problemas como interrupção da corrente no sistema $\mathrm{CE}$ e, o volume morto elevado na união dos capilares que leva a um aumento da dispersão, com conseqüiente perda de eficiência de separação. Desta forma, esta interface é pouco usada no acoplamento CE-MS. ${ }^{55,56}$

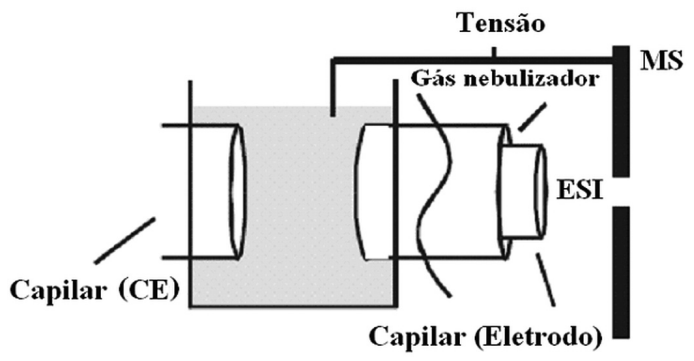

Figura 6. Interface CE-ESI-MS com junção líquida

\section{Modos de ionização e analisadores de massas}

Diversos modos de ionização podem ser empregados para o acoplamento CE-MS, tais como cf-FAB, ${ }^{57,58}$ ionização química à pressão atmosférica (APCI - atmospheric pressure chemical ionization), ${ }^{59,60}$ MALDI $^{61,62}$ e ESI. ${ }^{8,63}$ ESI é o mais comumente usado uma vez que transfere moléculas ionizadas da fase líquida diretamente para a fase gasosa. Outra característica interessante do ESI é que moléculas com alta massa molecular podem ser detectadas pela formação de íons multicarregados (já que a maioria dos espectrômetros de massas apresenta uma faixa limitada de valores de razão massa/carga $-\mathrm{m} / \mathrm{z}$ ). ${ }^{10}$

Diferentes analisadores de massas podem ser acoplados à CE, incluindo triplo quadrupolo, ressonância ciclotrônica de íons com transformada de Fourier, ${ }^{64-67}$ sistema de focalização dupla (seto- res elétrico e magnético), ${ }^{68,69}$ tempo de vôo ${ }^{70-72}$ e ion trap. ${ }^{61,62}$ Os quadrupolos são os analisadores mais comumente usados em CEMS, provavelmente devido a sua popularidade como detector de cromatografia e, conseqüientemente, seu menor custo. Entretanto, a baixa velocidade de varredura (fator limitante na detecção de picos eletroforéticos que apresentam alta eficiência), baixa resolução e sensibilidade (especialmente no modo scan) são as principais limitações destes analisadores. Já os analisadores ion trap, também encontrados em muitos laboratórios, representam uma boa opção para o acoplamento CE-MS por apresentarem melhores velocidades de varredura e sensibilidade, mas principalmente por poderem realizar múltiplos estágios de fragmentação $\left(\mathrm{MS}^{\mathrm{n}}\right)$ sem o custo adicional de instrumentos híbridos. ${ }^{5}$

\section{Limites de detecção e outras figuras de mérito}

O limite de detecção em CE-MS é influenciado, primeiramente, pelas características intrínsecas do equipamento de MS como, por exemplo, a plataforma de separação dos íons e configurações específicas dos esquemas de detecção de íons. Adicionalmente, o modelo de interface empregado, as condições em que essa interface é operada, as propriedades do eletrólito, a dimensão do capilar e outros parâmetros do sistema eletroforético influenciam a detectabilidade do sistema. ${ }^{8,63}$ $\mathrm{Na}$ literatura, encontram-se valores de quantidades mínimas detectadas para sistemas sheath liquid e sheathless na ordem de 3-20 e 0,1-5 fmol, respectivamente, na análise de peptídeos sintéticos. ${ }^{5}$

Grahama et al..$^{73}$ empregaram CE-MS na quantificação de 30 espécies de compostos encontrados em veneno de cobra (contendo moléculas relacionadas ao processo de vasodilatação), apresentando limites de detecção na ordem de $10 \mu \mathrm{mol} \mathrm{L}{ }^{-1}$. Soga et al. ${ }^{74}$ desenvolveram um método para determinação de 82 compostos (incluindo 9 ânions inorgânicos, 23 ácidos orgânicos, 18 aminoácidos e 32 carboidratos) em uma única análise, obtendo limites de detecção entre 0,1 e $14 \mu \mathrm{mol} \mathrm{L}^{-1}$, em um sistema CE-MS/MS com analisador triplo quadrupolo. Limites de detecção de $0,3-3,8 \mathrm{ng} \mathrm{mL}^{-1}$ foram obtidos na análise de anfetaminas em urina de humanos, utilizando extração em fase sólida (SPE - solid phase extraction) para pré-concentração e clean up da amostra. ${ }^{75}$

Conforme mencionado anteriormente, os menores limites de detecção são obtidos com a interface CE-MS sheathless, embora seja ainda pouco usada. Por exemplo, Edwards et al. ${ }^{76}$ conseguiram determinar 118 metabólitos relacionados à Escherichia coli com esta interface em uma única análise, obtendo limites de detecção de $20 \mathrm{nmol} \mathrm{L}{ }^{-1}$ a $2,5 \mu \mathrm{mol} \mathrm{L} \mathrm{L}^{-1}$. Wang et al. ${ }^{.7}$ desenvolveram um método para analisar nucleosídeos em urina de humanos com excelentes linearidades e limites de detecção na faixa de $0,00862-3,82 \mu \mathrm{mol} \mathrm{L} \mathrm{L}^{-1}$. Em outro exemplo, a separação de 7 isômeros D e L de fármacos foi realizada por CE-ESI-MS com limites de detecção de $0,1 \mu \mathrm{g} \mathrm{mL} \mathrm{mL}^{-1}$, em menos de 30 min. $^{78}$

Lara et al..$^{79}$ apresentaram um novo método combinando extração em fase sólida e CE-MS para analisar 11 giberelinas, o qual apresentou linearidade entre $0,984-0,995$, variação nos tempos de migração inferior a $0,8 \%$ e detectabilidade entre $0,31-1,02 \mu \mathrm{mol} \mathrm{L}{ }^{-1}$. Ge et al. ${ }^{80}$ desenvolveram e validaram um novo método analítico usando CE-MS/MS para analisar 12 sulfoamidas em carne suína, apresentando sensibilidade requerida pela decisão da Comunidade Européia (2002/657/EC European Decision). A faixa de linearidade (r) encontrada foi 0,996-0,997, a precisão das áreas dos picos foi inferior a $14 \%$, a faixa de recuperação foi $76-98 \%$ e os limites de quantificação variaram na faixa de $12,5-46,5 \mu \mathrm{g} \mathrm{kg}^{-1}$.

Sturm et al.$^{81}$ apresentaram um método para analisar interferentes (álcool aminos) em lubrificantes e líquidos refrigeradores (coolants) usando CE-MS e empregando eletrólitos não aquosos. O mesmo foi 
otimizado resultando em análises com tempo de migração inferiores a 9 min, sendo possível analisar 10 contaminantes. O método apresentou variação dos tempos de migração inferior a 1,5\%, linearidade entre 0,990-0,999, limite de detecção inferior a $1 \mathrm{mg} \mathrm{L}^{-1}$ e repetibilidade intra e inter dia inferior a $5 \%(\mathrm{n}=10)$.

Fekete et al. ${ }^{82}$ validaram um método para quantificar 8 quinonas de uso veterinário aplicadas em vacas leiteiras. Este método foi desenvolvido de acordo com a regulamentação da área na Comunidade Européia para estas formulações (EU Council Regulation $n^{\circ}$. 2377/90). Resultados satisfatórios foram encontrados, tais como linearidade entre 0,989-0,992, desvios de tempo de migração e área de picos inferiores a $18 \%$ e recuperação entre $81-110 \%$. Estes parâmentos foram inferiores aos requeridos na norma acima citada, o que indica que o método baseado em CZE-MS/MS para análise de antibióticos em controle e segurança de alimentos tem alto potencial de aplicação.

\section{APLICAÇÕES PARA CE-MS}

Nos últimos 20 anos a CE acoplada à MS vem ganhando notoriedade crescente como ferramenta analítica, ${ }^{2,9,63}$ e anualmente a revista científica mais importante na área de métodos eletroforéticos e técnicas afins, a Electrophoresis, dedica uma edição especial inteira a trabalhos exclusivos com CE-MS. ${ }^{83-85}$ A maioria dos trabalhos empregando esta técnica está relacionada às ciências da vida, ${ }^{86}$ todavia, encontram-se na literatura trabalhos nas mais diferentes áreas, envolvendo várias modalidades de eletroforese capilar acopladas à MS. ${ }^{31,87-90}$

Soga et al. ${ }^{91}$ desenvolvaram e determinaram 352 substâncias modelo relacionadas a rotas metabólicas conhecidas, o que é um resultado altamente satisfatório, empregando CE-MS como ferramenta analítica. Esta mesma metodologia baseada em CE-MS foi empregada, em outro trabalho, para analisar 1692 compostos oriundos do extrato da bactéria Bacillus subtilis (Figura 1S - Material Suplementar). Estes resultados geraram informações sobre mudanças no metabolismo durante a fase de esporulação. O mesmo grupo de pesquisa comprovou a possibilidade de separar compostos aniônicos relacionados a rotas metabólicas do B. subtilis..$^{92}$ As quantidades detectadas foram da ordem de fmol, o que tornou o método desenvolvido ainda mais atraente e de grande aplicabilidade para estudos desta natureza.

He et al. ${ }^{93}$ desenvolveram um método para a detecção de metabólitos diagnósticos em urina por CE-MS, obtendo um método mais específico e sensível que por detecção UV. Dentre os metabólitos investigados incluem-se os relacionados à deficiência de $\gamma$-glutamil transpeptidase, deficiência generalizada de glutationa, deficiência de adenilsuccinase, atrofia de girato e histidinemia. Há também vários trabalhos mostrando a eficiência do emprego de CE-MS em estudos metabólicos em fluidos biológicos de origem animal e vegetal..$^{94-97}$

Soga et al. ${ }^{98}$ descreveram um método para separação e detecção de 1.859 analitos em extratos de figado de rato e estudaram múltiplas mudanças em níveis metabólicos, incluindo a ativação da rota da biossíntese do oftalmato. Esse trabalho mostra que a CE-MS é uma poderosa ferramenta na descoberta de biomarcadores de baixa massa molecular, relacionados ao stress oxidativo.

A busca de métodos analíticos aplicados a análises clínicas, nas quais a disponibilidade de amostra é mínima (sangue, ou ainda mais criticamente, fluido cérebro-espinhal, por exemplo), tem recorrido à CE-MS como a técnica de escolha. Dentro desta necessidade, sistemas analíticos de CE utilizam menos que $10 \mathrm{~nL}$ de amostra por injeção, fazendo com que seja ideal para testes pediátricos, geriátricos e forenses. Em HPLC, mesmo em escala capilar, utiliza-se no mínimo $1 \mu \mathrm{L}$ em cada injeção. Smetkova et al. ${ }^{99}$ publicaram uma revisão sobre análise de morfina e compostos relacionados por LC e CE-MS. Diferentes modos de ionização à pressão atmosférica, bem como demais parâmetros relacionados à eficiência de ionização, foram discutidos. Concluiu-se que CE-MS é, por enquanto, menos usada que LC-MS nas análises de tais compostos, mas que tem grande potencial de aceitação devido às vantagens já citadas. A análise do entorpecente ecstasy e seus derivados em urina, usando CE-ESIMS, também é encontrada na literatura. ${ }^{100}$ Demais fármacos como cafeína, anfetamina e benzodiazepinas também já foram analisados pela técnica de CE-MS. ${ }^{101-104}$

Metodologias via CE-MS para analisar proteínas glico-conjugadas em urina de pacientes foram também desenvolvidas, as quais auxiliam o diagnóstico de várias desordens metabólicas, tais como Diabete mellitus e outras doenças que afetam o metabolismo em geral. ${ }^{101,105-107} \mathrm{~A}$ descoberta de biomarcadores relacionados a desordens metabólicas em organismos humanos, tais como doença de Alzheimer, tornou-se vital para o diagnóstico do estágio inicial da doença, bem como para a compreensão do seu mecanismo. A alta resolução de CE ajuda na identificação de amostras complexas, geralmente eliminando etapas de isolamento prévio, e a alta sensibilidade da MS auxilia a descoberta de biomarcadores no estágio inicial de disfunções metabólicas. ${ }^{108}$ Desta forma, desde 2003, métodos baseados em CE-MS passaram a ser reconhecidos na Comunidade Européia como metodologia oficial para diagnósticos. ${ }^{109}$ Lord et al.${ }^{110}$ relataram a análise do ácido 5-aminolevulínico (ALA) e do porfobilinogênio (PBG), dois metabólitos relacionados à porfiria aguda intermitente (PAI), por CE-MS com níveis de detecção suficientes para fornecer um diagnóstico rápido e preciso da doença.

Em estudos proteômicos, a técnica de eletroforese em gel de poliacrilamida bidimensional (2D-PAGE) é amplamente usada, embora apresente várias limitações, que levaram ao desenvolvimento de sistemas complementares, como a cromatografia bidimensional. Entretanto, a CE oferece possibilidade de, no futuro, superar os sistemas eletroforéticos convencionais, frente à diversidade de mecanismos de separação. Recentemente, trabalhos envolvendo estudos proteômicos são encontrados na literatura, os quais comprovam a evolução de CE-MS aplicada neste tipo de estudos. ${ }^{111-115}$

A técnica de CE-MS também pode ser empregada na análise de resíduos de pesticidas em alimentos. O limite de detecção obtido é pelo menos uma ordem de grandeza menor que em CE-UV e, concomitantemente, menor que os permitidos por lei (limite máximo permitido para o resíduo) aumentando, portanto, a aplicabilidade desta técnica. A análise de ácidos nucléicos, bem como seus adutos, também já foi realizada por CE-MS. No segundo caso, adutos de benzo[a] pireno foram avaliados, uma vez que são compostos policíclicos aromáticos presentes no meio ambiente. ${ }^{116}$ Novos procedimentos de preparação de amostra, a fim de eliminar os nucleotídeos não adutos, foram discutidos, como extração em fase sólida com afinidade por metais. ${ }^{117}$

Outra aplicação de grande interesse é a análise de aminoácidos em alimentos, por necessitar de métodos quantitativos e precisos. A análise de aminoácidos é particularmente desafiadora devido ao fato que a maioria dos aminoácidos não absorve na região $\mathrm{UV}$, requerendo derivatização da amostra e levando a maior fonte de erros. ${ }^{63} \mathrm{O}$ sistema CE-MS é o ideal para análise qualitativa e quantitativa de aminoácidos em alimentos devido à sua precisão e sensibilidade, embora o custo da análise ainda seja alto. Alguns trabalhos na literatura demonstraram a utilidade e confiabilidade de CE-MS para a análise de aminoácidos (Figura 7). ${ }^{74}$ Nestes trabalhos, a CE-MS apresenta um grande avanço uma vez que a pequena diferença de mobilidade entre alguns aminoácidos sempre foi um empecilho nas separações envolvendo outras modalidades 
de CE. Porém, a combinação de artefatos, tais como o uso de pressão na separação e aditivos no eletrólito, aliados a ferramentas computacionais possibilitou a análise eficiente e a quantificação de aminoácidos em diferentes matrizes. , $^{269,84,112}$ A extração em fase sólida previamente à análise por CE-MS contribui para o aumento da detectabilidade dos métodos de análise de alimentos, como leite de soja, ${ }^{118}$ pêssego, nectarina, ${ }^{119}$ sucos de uva e laranja. ${ }^{120} \mathrm{Um}$ estudo envolvendo a avaliação de diferentes métodos de hidrólises da proteína albumina soro bovina (BSA - bovine serum albumin) usando CE-MS para análise dos aminoácidos resultantes mostrou a utilidade e aplicabilidade da técnica, empregando a castanha do pará como amostra real. ${ }^{121}$

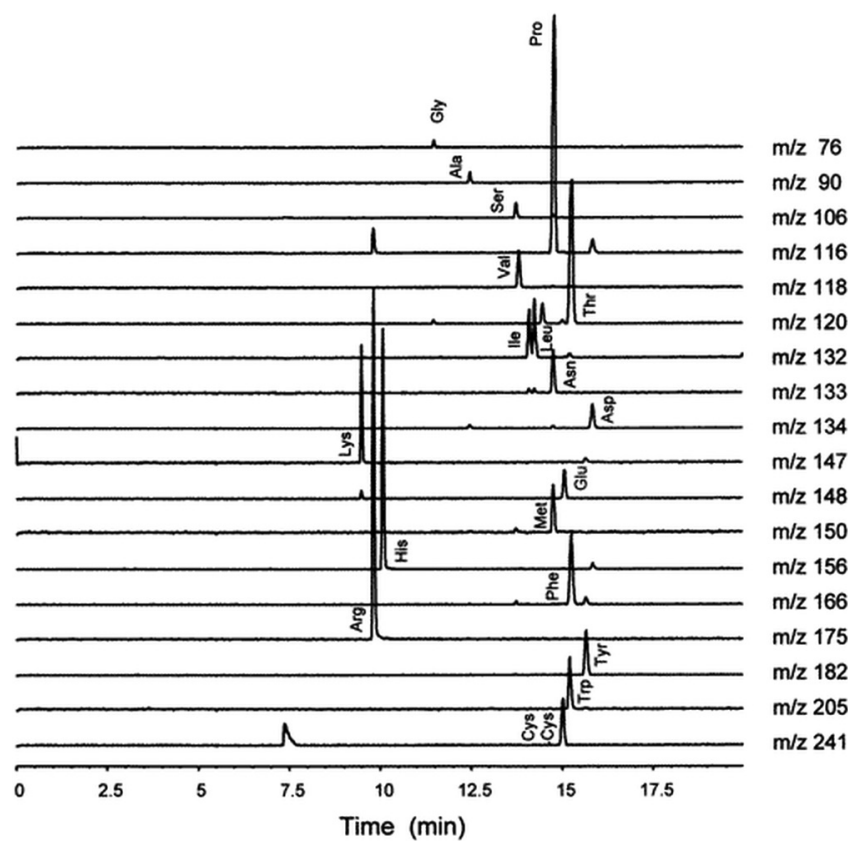

Figura 7. EIEs (Extracted Ion Electropherograms) de aminoácidos presentes em molho de soja. Reproduzida da ref. 91 com permissão da ACS

Na Tabela 1 é mostrado um panorama geral das principais aplicações de CE-MS em proteoma, metaboloma, separações enantioméricas, forenses, ambientais e clínicas.

\section{O ESTADO DA ARTE E PERSPECTIVAS DA EVOLUÇÃO DE CE-MS NO BRASIL}

O grupo de pesquisa do Prof. Dr. Etelvino J. H. Bechara tem como interesse o desenvolvimento de metodologias analíticas e bioanalíticas com CE-ESI-MS/MS ${ }^{\mathrm{n}}$ relacionado a vários enfoques. Um deles é a busca de biomarcadores para o estudo de mecanismos relacionados ao estresse redox e carbonílico associado a $\alpha$-aminocetonas e $\beta$-cetoácidos endógenos. Estes estudos estão relacionados a varias desordens metabólicas. Sabe-se hoje que $\mathrm{O}_{2}$ e NO atuam como parceiros no metabolismo normal e que desequilíbrios nesta cooperação produzem danos oxidativos e nitrosativos em biomoléculas e organelas, ameaçando a vida da célula. Outra linha de estudo é a atividade pró-oxidante e acilante de metabólitos de aminoácidos, particularmente $\alpha$-aminocetonas e $\beta$-cetoácidos, que são acumulados nos tecidos de portadores de desordens. Nos próximos anos a investigação dos mecanismos de oxidação aeróbica dos metabólitos: ácido 5-aminolevulínico (ALA); aminocetona (AA); succinilcetona (SA) e metil aceto acetato (MAA), bem como os efeitos deletérios de seus produtos de oxidação finais - ácido 4,5-dióxidovalérico (DOVA), metilglioxal (MG) e biacetilo - sobre células em cultura, ratos e humanos será continuada. Uma das principais ferramentas para este estudo está em metodologias baseadas em CE-ESI/MS ${ }^{\mathrm{n}}$ para análise destes metabólitos e busca de marcadores relacionados ao estresse carbonílico.

A Profa. Dra. Marina F. M. Tavares supervisiona o laboratório de cromatografia e eletroforese capilar (LACE), fundado em 1997 no IQ-USP. Seus interesses de pesquisa relacionam-se com separações em meio líquido, cromatografia e eletroforese capilar de alta eficiência, em tópicos de cunho fundamental e aplicado, centrados em compostos de importância clínica, forense e ambiental, além de fármacos, alimentos e produtos naturais. A linha de pesquisa que abrange aspectos fundamentais inclui estudos dos mecanismos de separação, modelos de migração eletroforética e eletroosmótica, interação soluto-micela, equilíbrios ácido-base e de complexação, otimização de separações e estratégias de pré-concentração on-line. A linha clínica inclui a avaliação de metabólitos (hemoglobina glicada, cetoácidos, hormônios esteroidais) em fluidos biológicos (sangue e urina), enquanto que a área forense inclui a investigação de drogas de abuso (opióides, canabinóides, anfetaminas) em fluidos biológicos alternativos (cabelo e humor vítreo). A área ambiental contempla estudos sobre emissões veiculares e poluentes no ar atmosférico (aldeídos e cetonas) e águas de abastecimento (fármacos, pesticidas, azo-corantes). A linha de fármacos inclui investigação de pureza e controle de qualidade de fármacos anti-retrovirais (coquetel AIDS) e anti-câncer (ftalocianinas metaladas). Em alimentos, o foco está na análise de constituintes (carboidratos, ácidos graxos, ácidos carboxílicos, compostos fenólicos e aminoácidos), aditivos (corantes e vitaminas) e contaminantes (pesticidas). $\mathrm{Na}$ linha de produtos naturais, há interesse na caracterização de extratos vegetais (compostos fenólicos), óleos essenciais e hidrolisados de proteína de interesse cosmiátrico ou fitoterápico.

O Laboratório de Bioanalítica, Microfabricação e Separações BioMicS - tem como metas o desenvolvimento de instrumentação analítica em métododos eletroforéticos, em particular no desenvolvimento de microchips de separação. Visa também o desenvolvimento de metodologias bioanalíticas que possam contribuir não só para um melhor diagnóstico de doenças, mas também para o entendimento dos processos biológicos envolvidos. Para tanto, atua nas áreas de genômica e análises genéticas, proteômica e análises de proteínas, e metabolômica e análise de metabólitos secundários de plantas e microrganismos. Com exceção das análises genéticas, as áreas de proteômica e metabolômica são essencialmente depententes de espectrometria de massas e a utilização de CE-MS é fundamental para o sucesso de tais projetos. Alguns exemplos de desenvolvimentos nesta direção, começando pela instrumentação, são o acoplamento de microchips ou MS, desenvolvimento de colunas especiais para CEMS sheathless, microcolunas empacotadas para eletrocromatografia e métodos eletroforéticos em meio não-aquoso. ${ }^{28}$ Particularmente na área de proteômica, o foco é voltado para a proteômica clínica, buscando biomarcadores para diagnóstico precoce de doenças e no entendimento de como algumas doenças evoluem, como esquizofrenia e Alzheimer. O interesse em metabólitos secundários abrange desde a detecção e identificação estrutural de novos metabólitos biologicamente ativos, ${ }^{122,129}$ até o entendimento de rotas metabólicas e mecanismo de ação de proteínas numa abordagem mais ampla de química biológica e biologia de sistemas.

\section{MATERIAL SUPLEMENTAR}

No material suplementar, disponível gratuitamente em http:// quimicanova.sbq.org.br, na forma de arquivo PDF, encontra-se a Figura $1 \mathrm{~S}$, que contém eletroferogramas dos íons extraídos (EIEs) de metabólitos catiônicos da bactéria Bacillus subtilis. ${ }^{91}$ 
Tabela 1. Principais aplicações de CE-MS

\begin{tabular}{|c|c|c|c|c|c|c|}
\hline Aplicação & Analito & Matriz & Modalidade de CE & $\begin{array}{l}\text { Interface, modo de } \\
\text { ionização } \\
\end{array}$ & $\begin{array}{c}\text { Analisador } \\
\text { de MS }\end{array}$ & Ref. \\
\hline \multirow{4}{*}{ Proteômica } & Biomarcadores de doenças renais & Urina Humana & CZE & Sheath liquid & TOF & 114 \\
\hline & Biomarcadores de doenças renais & Urina Humana & CZE & Sheath liquid, ESI & TOF & 122 \\
\hline & Biomarcadores de câncer de próstata & Urina humana & $\mathrm{CZE}$ & Sheath liquid, ESI & $\mathrm{TOF}$ & 123 \\
\hline & Digerido proteico de patógenos & $\begin{array}{l}\text { Pus, escarro e urina } \\
\text { de humanos }\end{array}$ & CZE & Sheath liquid, ESI & Ion trap & $\begin{array}{c}93 \\
124\end{array}$ \\
\hline \multirow{13}{*}{ Metabolômica } & $\begin{array}{l}\text { Glutationa, piroglutamato, adenil } \\
\text { succinato, ornitina, histidina e ácido } \\
\text { homogenístico }\end{array}$ & Urina humana & CZE & Sheath liquid, ESI & Ion trap & \\
\hline & Metabólitos de haloperidol & Urina humana & CZE & Sheath liquid, ESI & Quadrupolo & 125 \\
\hline & $\begin{array}{l}\text { Isômeros de anfetaminas e pseudo- } \\
\text { efedrina }\end{array}$ & Urina humana & CZE & Sheath liquid, ESI & Quadrupolo & 78 \\
\hline & Isômeros de tramadol & Plasma humano & CZE-partial filling & Sheath liquid, ESI & Quadrupolo & 126 \\
\hline & $\begin{array}{c}\text { Ácidos orgânicos, aminoácidos e } \\
\text { açúcares }\end{array}$ & Arroz transgênico & CZE & Sheath liquid, ESI & N.I.* & 127 \\
\hline & $\begin{array}{c}\text { Metabólitos das vias glicolítica e } \\
\text { pentose fosfato, do ciclo do ácido } \\
\text { tricarboxílico da foto-respiração e da } \\
\text { biossíntese de aminoácidos }\end{array}$ & Folha de arroz & CZE & Sheath liquid, ESI & $\begin{array}{c}\text { Triplo } \\
\text { quadrupolo }\end{array}$ & 128 \\
\hline & Sideróforos & Extrato bacteriano & CZE & Sheath liquid, ESI & Ion trap & 129 \\
\hline & $\begin{array}{c}\text { Metabólitos aniônicos, catiônicos, } \\
\text { nucleotídeos e derivados de CoA }\end{array}$ & $\begin{array}{l}\text { Extrato de Bacillus } \\
\text { subtillis }\end{array}$ & CZE & Sheath liquid, ESI & $\begin{array}{c}\text { Triplo } \\
\text { quadrupolo }\end{array}$ & 92 \\
\hline & Nucleotídeos glicosilados & Extrato celular & CZE & Sheath liquid, ESI & $\begin{array}{l}\text { Linear } \\
\text { Ion trap }\end{array}$ & 130 \\
\hline & Metabólitos ácidos e fosforilados & $\begin{array}{l}\text { Extratos de } \\
\text { procariotos }\end{array}$ & CZE & Sheathless, ESI & Ion trap & 76 \\
\hline & Metabólitos bacterianos & Escherichia coli & CZE & Sheath liquid, ESI & Ion trap & 131 \\
\hline & Enzimas bacterianas & Escherichia coli & CZE & Sheath liquid, ESI & $\begin{array}{l}\text { Quadrupolo } \\
\text { e TOF }\end{array}$ & 132 \\
\hline & $\begin{array}{c}\text { Glicofosfatos, ácidos orgânicos, } \\
\text { nucleotídeos e compostos derivados } \\
\text { da coenzima A (CoA) }\end{array}$ & Padrões analíticos & $\begin{array}{l}\text { CZE com aplicação } \\
\text { de pressão } \\
\text { (polaridade reversa) }\end{array}$ & Sheath liquid, ESI & Ion trap & 133 \\
\hline \multirow{14}{*}{$\begin{array}{l}\text { Farmacêutica/ } \\
\text { Separações } \\
\text { enantioméricas }\end{array}$} & Drogas de abuso & Urina humana & $\mathrm{CZE}$ & Sheath liquid, ESI & Quadrupolo & 134 \\
\hline & Fármaco & Urina humana & CZE-NACE & Sheath liquid, ESI & Ion trap & 135 \\
\hline & Fármaco & Urina humana & CZE & Sheath liquid, ESI & N. I. & 136 \\
\hline & Fármacos para doenças pulmonares & Plasma & CZE & Sheath liquid, ESI & $\begin{array}{c}\text { Triplo } \\
\text { quadrupolo }\end{array}$ & 137 \\
\hline & Fármacos e metabólitos & Soro & CZE-partial-filling & Sheath liquid, ESI & Quadrupolo & 138 \\
\hline & Fármacos & Plasma de macaco & CZE & $\begin{array}{l}\text { Sheath liquid, ESI } \\
\text { e API }\end{array}$ & $\begin{array}{l}\text { Triplo } \\
\text { quadrupolo } \\
\text { e TOF }\end{array}$ & 139 \\
\hline & $\begin{array}{l}\text { Aminoácidos relacionados com } \\
\text { desordens metabólicas }\end{array}$ & Sangue & CZE & Sheathless, ESI & Ion trap & 140 \\
\hline & Impureza em composto antifúngicos & Fármacos & CZE & Sheath liquid, ESI & Ion trap & 141 \\
\hline & Fármacos anestésicos & Formulações & CZE-partial-filling & Sheath liquid, ESI & Quadrupolo & 142 \\
\hline & Forense/ Drogas de abuso & Solução de padrões & CZE & Sheath liquid, ESI & $\begin{array}{l}\text { Quadrupolo- } \\
\text { TOF }\end{array}$ & 143 \\
\hline & Fármacos & Solução de padrões & CZE-partial-filling & $\begin{array}{l}\text { Sheath liquid, ion } \\
\text { spray }\end{array}$ & Quadrupolo & 144 \\
\hline & Antibióticos & Solução de padrões & CZE & Sheath liquid, ESI & Quadrupolo & 145 \\
\hline & Fármacos & Solução de padrões & CZE & N.I., ESI & $\begin{array}{l}\text { Triplo qua- } \\
\text { drupolo }\end{array}$ & 146 \\
\hline & Herbicidas & Solução de padrões & CZE & Sheath liquid, ESI & Ion trap & 147 \\
\hline
\end{tabular}


Tabela 1. continuação

\begin{tabular}{|c|c|c|c|c|c|c|}
\hline Aplicação & Analito & Matriz & Modalidade de CE & $\begin{array}{l}\text { Interface, modo de } \\
\text { ionização }\end{array}$ & $\begin{array}{c}\text { Analisador } \\
\text { de MS }\end{array}$ & Ref. \\
\hline \multirow{4}{*}{ Forense } & $\beta$-carbonilas & Extratos de plantas & CZE & Sheath liquid, ESI & Ion trap & 148 \\
\hline & Morfina e anfetamina & Urina & CZE & Sheath liquid, ESI & Ion trap & 149 \\
\hline & Anfetaminas & Urina humana & CZE & Sheath liquid, ESI & Ion trap & 104 \\
\hline & Ópio & Extrato de planta & CZE & Sheath liquid, ESI & TOF & 150 \\
\hline \multirow{8}{*}{ Ambiental } & Herbicida & Água & CZE-NACE & Sheath liquid, ESI & Ion trap & 151 \\
\hline & Espécies metálicas & Solo & CZE & $\begin{array}{l}\text { Sheath liquid, } \\
\text { ICP** }\end{array}$ & N.I. & 152 \\
\hline & Antimônio & Esgoto & CZE & Sheath liquid, ICP & N.I. & 153 \\
\hline & Glicoproteínas associadas ao câncer & Urina humano & CZE & $M A L D I$ & TOF & 154 \\
\hline & $\begin{array}{c}\text { Derivado de boro } \\
\text { (drogas anticancerígenas) }\end{array}$ & Urina humana & CZE & Sheath liquid, ESI & Ion trap & 155 \\
\hline & Borofenilalanina & Tecidos humanos & CZE & Sheath liquid, ICP & $\begin{array}{l}\text { Setor eletro- } \\
\text { magnético }\end{array}$ & 156 \\
\hline & Serotonina e precursores & Plasma humano & CZE & Sheath liquid, ESI & TOF & 157 \\
\hline & Metaloproteínas anti-cancerígenas & Soro & CZE & Sheath liquid, ICP & N.I & 158 \\
\hline
\end{tabular}

*N.I.: não informado. **ICP: plasma acoplado indutivamente

\section{AGRADECIMENTOS}

À Fundação de Amparo à Pesquisa do Estado de São Paulo (FAPESP), pelo apoio financeiro aos projetos de pesquisa, dos grupos envolvidos e bolsa de pós-doutorado, mas especialmente pelo financiamento dos dois equipamentos CE-MS, e ao Conselho Nacional de Desenvolvimento Científico e Tecnológico (CNPq) pelas bolsas de pós-doutorado e de pesquisa em produtividade.

\section{REFERÊNCIAS}

1. Nilsson, S.; Tese de Doutorado, University of Uppsala, Suécia, 2004.

2. Schmitt-Kopplin, P.; Frommberger, M.; Electrophoresis 2003, 24, 3837.

3. Aebersold, R.; Mann, M.; Nature 2003, 422, 198

4. Mann, M.; Hendrickson, R. C.; Pandey, A.; Annu. Rev. Biochem. 2001, $70,437$.

5. Hernández-Borges, J.; Neusüß, C.; Cifuentes, A.; Pelzing, M.; Electrophoresis 2004, 25, 2257.

6. Yates, J. R.; J. Mass Spectrom. 1998, 33, 1.

7. Mol, R.; de Jong, G. J.; Somsen, G. W.; Electrophoresis 2005, 26, 146.

8. Olivares, J. A.; Nguyen, N. T.; Yonker, C. R.; Smith, R. D.; Anal. Chem. 1987, 59, 1230.

9. Petersen, J. R.; Mohammad, A. M.; Clinical and Forensic Applications of Capillary Electrophoresis, Humana Press: Totowa, 2001.

10. Schmitt-Kopplin, P.; Englmann, M.; Electrophoresis 2005, 26, 1209.

11. Keough, T.; Takigiku, R.; Lacey, M. P.; Purdon, M.; Anal. Chem. 1992, 64, 1594.

12. Weinmann, W.; Parker, C. E.; Baumeister, K.; Maier, C.; Tomer K. B.; Przybylski M.; Electrophoresis 1994, 15, 228.

13. Weinmann, W.; Baumeister, K.; Kaufmann, I.; Przybylski, M.; J. Chromatogr. 1993, 628, 111.

14. Van Veelen, P. A.; Tjaden, U. R.; Van Der Greef, J.; Ingendoh, A.; Hillenkamp, F.; J. Chromatogr. 1993, 647, 367.

15. Suter, M. J. F.; Caprioli, R. M.; J. Am. Soc. Mass Spectrom. 1992, 3, 198.

16. Moseley, M. A.; Deterding, L. J.; Dewit, J. S. M.; Tomer, K. B.; Kennedy, R. T.; Bragg, N.; Jorgenson, J. W.; Anal. Chem. 1989, 61, 1577.

17. Moseley, M. A.; Deterding, L. J.; Tomer, K. B.; Jorgenson, J. W.; J.
Chromatogr. 1990, 516, 167.

18. Moseley, M. A.; Deterding, L. J.; Tomer, K. B.; Jorgenson, J. W.; J. Chromatogr. 1989, 480, 197.

19. Foret, F.; Thompson, T. J.; Vouros, P.; Karger, B. L.; Gebauer, P.; Bocek, P.; Anal. Chem. 1994, 66, 4450.

20. Pleasance, S.; Thibault P.; Kelly, J.; J. Chromatogr. 1992, 591, 325.

21. Caprioli, R. M.; Moore, W. T.; Martin, M.; Dague B. B.; Wilson, K.; Moring, S.; J. Chromatogr. 1989, 480, 247.

22. Scriba, G. K. E.; J. Chromatogr., A 2007, 1159, 28.

23. Klampfl, C. W.; J. Chromatogr., A 2004, 1044, 131.

24. Barceló-Barrachina, E.; Moyano, E.; Galceran, M. T.; Electrophoresis 2004, 25, 1927

25. Tomlinson, A. J.; Benson, L. M.; Gorrod, J. W.; Naylor, S.; J. Chromatogr., B: Anal. Technol. Biomed. Life Sci. 1994, 657, 373.

26. Peri-Okonny, U. L.; Kenndler, E.; Stubbs, R. J.; Guzman, N. A.; Electrophoresis 2003, 24, 139.

27. Ballard, J. N. M.; Lajoie, G. A.; Yeung, K. K. C.; J. Chromatogr., A 2007, 1156, 101.

28. Assunção, N. A.; Deziderio, L. A. G.; Paulino, L. G.; Lupetti, K. O.; Carrilho, E.; Electrophoresis 2005, 26, 3292.

29. Steiner, F.; Hassel, M.; Electrophoresis 2003, 24, 399.

30. Senior, J.; Rolland, D.; Tolson, D.; Chantzis, S.; De Biasi, V.; J. Pharm. Biomed. Anal. 2000, 22, 413.

31. Hofstadler, S. A.; Wahl, J. H.; Bruce, J. E.; Smith, R. D.; J. Am. Chem. Soc. 1993, 115, 6983 .

32. Von Brocke, A.; Nicholson, G.; Bayer, E.; Electrophoresis 2001, 22 , 1251.

33. Fenn, J. B.; Mann, M.; Meng, C. K.; Wong, S. F.; Whitehouse C. M.; Mass Spectrom. Rev. 1990, 9, 37.

34. Viberg, P.; Nilsson, S.; Skoog, K.; Anal. Chem. 2004, 76, 4241.

35. Tanaka, Y.; Kishimoto, Y.; Terabe, S.; J. Chromatogr., A 1998, 802, 83.

36. Nelson, W. M.; Lee, C. S.; Anal. Chem. 1996, 68, 3265.

37. Uijselaar, P. G.; Otsuka, K.; Terabe, S.; J. Chromatogr. 1998, 802, 3.

38. Shamsi, S. A.; Electrophoresis 2002, 23, 4036.

39. Xue, Q.; Foret, F.; Dunayevskiy, Y. M.; Zavracky, P. M.; McGruer, N. E.; Karger, B. L.; Anal. Chem. 1997, 69, 426.

40. Razunguzwa, T.; Timperman, A. T.; Methods Mol. Biol. 2006, 339, 67.

41. Akashi, S.; Suzuki, K.; Arai, A.; Yamada, N.; Suzuki, E. I.; Hirayama, K.; Nakamura, S.; Nishimura, Y.; Rapid Commun. Mass Spectrom. 2006, 20, 1932. 
42. Dahlin, A. P.; Wetterhall, M.; Liljegren, G.; Bergstrom, S. K.; Andrén, P.; Nyholm, L.; Markides, K. E.; Bergquist, J.; Analyst 2005, 130, 193.

43. Song, Q. J.; Greenway, G. M.; McCreedy, T.; J. Anal. At. Spectrom. 2003, 18,1 .

44. Schoenherr, R. M.; Ye, M.; Vannatta, M.; Dovichi, N. J.; Anal. Chem. 2007, 79, 2230.

45. Kameoka, J.; Craighead, H. G.; Zhang, H.; Henion, J.; Anal.Chem. 2001, 73, 1935.

46. Licklider, L. K.; Werner, G.; Lacey, M. P.; Keough, T.; Purdon, M. P.; Takigiku, R.; Anal. Chem. 1995, 67, 4170.

47. Stomakhin, A. A.; Vasiliskov, V. A.; Timofeev, E.; Schulga, D.; Cotter, R. J.; Mirzabekov, A. D.; Nucleic Acids Res. 2000, 28, 1193.

48. Ro, K. W.; Liu, J.; Knapp, D. R.; J. Chromatogr., A 2006, 1111, 40.

49. Musyimi, H. K.; Guy, J.; Narcisse, D. A.; Soper, S. A.; Murray, K. K.; Electrophoresis 2005, 26, 4703.

50. Jin, L. J.; Ferrance, J.; Sanders, J. C.; Landers, J. P.; Lab on a Chip 2003, 3,11 .

51. Chen, W.; Shen, J.; Yin, X.; Yu, Y.; Rapid Commun. Mass Spectrom. 2007, 21, 35 .

52. Serwe, M.; Ross, G.; Chromatographia 1999, 49, S73.

53. Lu, M.; Tong, P.; Xiao, H.; Xia, S.; Zheng, X.; Liu, W.; Zhang, L.; Chen, G.; Electrophoresis 2007, 28, 1461.

54. Liu, C. C.; Alary, J. F.; Vollmerhaus, P.; Kadkhodayan, M.; Electrophoresis 2005, 26, 1366.

55. Sheppard, R. L.; Henion, J.; Electrophoresis 2002, 18, 287.

56. Garcia, F.; Henion, J. D.; Anal. Chem. 1992, 64, 985.

57. Caprioli, R. M.; Moore, W. T.; Martin, M.; DaGue, B. B.; J. Chromatogr. 1989, 480, 247.

58. Wolf, S. M.; Vouros, P.; J. Chromatogr. 1995, 480, 247.

59. Takada, Y.; Sakairi, M.; Koizumi, H.; Anal. Chem. 1995, 67, 1474.

60. Tanaka, Y.; Otsuka, K.; Terabe, S.; J. Pharm. Biomed. Anal. 2003, 30, 1889.

61. Rejtar, T.; Hu, P.; Juhasz, P.; Campbell, J. M.; Vestal, M. L.; Preisler, J.; Karger, B. L.; J. Proteome Res. 2002, 1, 171.

62. Preisler, J.; Hu, P.; Rejtar, T.; Moskovets, E.; Karger, B. L.; Anal. Chem. 2002, 74, 17.

63. Landers, J. P. Em Handbook of Capillary Electrophoresis; $2^{\text {nd }}$ ed.; Servers, J. C.; Smith, R. D., eds.; CRC Press: Boca Raton, 1997.

64. Hofstadler, S. A.; Swanek, F. D.; Gale, D. C.; Ewing, A. G.; Smith, R. D.; Anal. Chem. 1995, 67, 1477.

65. Severs, J. C.; Hofstadler, S. A.; Zhao, Z.; Senh, R. T.; Smith, R. O.; Electrophoresis 1996, 17, 1808

66. Castoro, J. A.; Chiu, R. W.; Monnig, C. A.; Wilkins, C. L.; J. Am. Chem. Soc. 1992, 114, 7571

67. Hofstadler, S. A.; Wahl, J. H.; Bruce, J. E.; Smith, R. D.; J. Am. Chem. Soc. 1993, 115, 6983.

68. Perkins, J. R.; Tomer, K. B.; Anal. Chem. 1994, 66, 2835.

69. Prange, A.; Schaumloffel, D.; Bratter, P.; Richarz, A. N.; Wolf, C.; Fresenius J. Anal. Chem. 2001, 371, 764.

70. Andón, B.; Barbosa, J.; Sanz-Nebot, V.; Electrophoresis 2006, 27, 3661.

71. Zhu, K.; Kim, J.; Yoo, C.; Miller, F. R.; Lubman, D. M.; Anal. Chem. 2003, 75, 6209

72. Brenner-Weiss, G.; Kirschofer, F.; Kuhl, B.; Nusser, M.; Obst, U.; J. Chromatogr., A 2003, 1009, 147

73. Grahama, R. L. J.; McCleana, S.; O'Kanea, E. J.; Theakstonb, D.; Shawc, C.; Biochem. Biophys. Res. Commun. 2005, 333, 88.

74. Soga, T.; Neiger, D. N.; Anal. Chem. 2000, 72, 1236.

75. Boatto, G.; Nieddu, M.; Carta, A.; Pau, A.; Palomba, M.; Asproni, B.; Cerri, R.; J. Chromatogr., B: Anal. Technol. Biomed. Life Sci.2005, 814, 93.

76. Edwards, J. L.; Chisolm, C. N.; Shackman, J. G.; Kennedy, R. T.; J. Chromatogr., A 2006, 1106, 80.
77. Wang, S.; Zhao, X.; Mao, Y.; Cheng, Y.; J. Chromatogr., A 2007, 1147, 254.

78. Iio, R.; Chinaka, S.; Takayama, N.; Hayakawa, K.; J. Health Sci. 2005, $51,693$.

79. Lara, F. J.; García-Campaña, A. M.; Alés-Barrero, F.; Bosque-Sendra, J. M.; García-Ayuso, L. E.; Anal. Chem. 2006, 78, 7665.

80. Ge, L.; Peh, C. Y. C.; Yong, J. W. H.; Tan, S. N.; Hua, L.; Ong, E. S.; J. Chromatogr., A 2007, 1159, 242.

81. Sturm, S.; Strasser, E. M.; Stuppner, H.; J. Chromatogr., A 2006, 1112, 331

82. Fekete, A.; Hertkorn, N.; Frommberger, M.; Lahaniatis, M. R.; Kettrup A.; Schmitt-Kopplin, P.; Electrophoresis 2006, 27, 2216.

83. Electrophoresis, 2004. Special Issue: Paper Symposium Capillary Electrophoresis/Mass Spectrometry, 25, 1927-2108.

84. Electrophoresis, 2006. Special Issue: Capillary Electrophoresis - Mass Spectrometry, 27, 2025-2259.

85. Electrophoresis 2007. Special Issue: Capillary - Mass Spectrometry, 28, 1303-1473.

86. Kolch, W.; Neusuß, C.; Pelzing, M.; Mischak, H.; Mass Spectrom. Rev. 2005, 24, 959 .

87. Banks, J. F.; Electrophoresis 1997, 18, 2255.

88. Simpson, D. C.; Smith, R. D.; Electrophoresis 2005, 26, 1291

89. Henion, J. D.; Mordehai, A. V.; Cai, J.; Anal. Chem. 1994, 66, 2103

90. Sheppard, R. L.; Tong, X.; Cai, J.; Henion, J. D.; Anal. Chem. 1995, 67, 2054.

91. Soga, T.; Ohashi, Y.; Ueno, Y.; Naraoka, H.; Tomita, M.; Nishioka, T.; J. Proteome Res. 2003, 2, 488.

92. Soga, T.; Ueno, Y.; Naraoka, H.; Ohashi, Y.; Tomita, M.; Nishioka, T.; Anal. Chem. 2002, 74, 2233.

93. He, T.; Quinn, D.; Fu, E.; Wang, Y. K.; J. Chromatogr., B: Anal. Technol. Biomed. Life Sci. 1999, 727, 43.

94. Zhao, X.; Lu, Y.; Phillips, D. R.; Hwang, H. M.; Hardin, I. R.; J. Chromatogr., A 2007, 1159, 217.

95. Tanaka, Y.; Higashi, T.; Rakwal, R.; Wakida, S.; Iwahashi, H.; J. Pharm. Biomed. Anal. 2007, 44, 608 .

96. Takahashi, H.; Hayashi, M.; Goto, F.; Sato, S.; Soga, T.; Nishioka, T.; Tomita, M.; Kawai-Yamada, M.; Uchimiya, H.; Annals of Botany 2006, $98,819$.

97. Bezy, V.; Chaimbault, P.; Morin, P.; Unger, S. E.; Bernard, M. C.; Agrofoglio, L. A.; Electrophoresis 2006, 27, 2464.

98. Soga, T.; Baran, R.; Suematsu, M.; Ueno, Y.; Ikeda, S.; Sakurakawa, T.; Kakazu, Y.; Ishikawa, T.; Robert, M.; Nishioka, T.; Tomita, M.; J. Biol. Chem. 2006, 281, 16768.

99. Smetkova, M.; Ondra, P.; Lemr, K.; Chemicke Listy 2004, 98, 336.

100. Varesio, E.; Cherkaoui, S.; Veuthey, J. L.; J. High Res. Chromatogr. 1998, 21, 653.

101. Peri-Okonny, U. L.; Wang, S. X.; Stubbs, R. J.; Guzman, N. A.; Electrophoresis 2005, 26, 2652

102. Ma, Y.; Liu, G.; Du, M.; Stayton, I.; Electrophoresis 2004, 25, 1473.

103. Sheppard, R. L.; Henion, J.; Anal. Chem. 1997, 69, 2901.

104. Ramseier, A.; Siethoff, C.; Caslavska, J.; Thormann, W.; Electrophoresis 2000, 21, 380.

105. Fliser, D.; Wittke, S.; Mischak, H.; Electrophoresis 2005, 26, 2708.

106. Kaiser, T.; Kamal, H.; Rank, A.; Kolb, H. J.; Holler, E.; Ganser, A.; Hertenstein, B.; Mischak, H.; Weissinger, E. M.; Blood 2004, 104, 340.

107. Kaiser, T.; Wittke, S.; Just, I.; Krebs, R.; Bartel, S.; Filser, D.; Mischak, H.; Weissinger, E. M.; Electrophoresis 2004, 25, 2044

108. Wittke, S.; Mischak, H.; Walden, M.; Kolch, W.; Radler, T.; Wiedemann, K.; Electrophoresis 2005, 26, 1476.

109. Manley, S.; John, W. G.; Marshall, S.; Diabetic Medicine 2004, 21, 673.

110. Lord, G. A.; Luo, J. L.; Lim, C. K.; Rapid Commun. Mass Spectrom. 2000, 14, 314. 
111. Stutz, H.; Electrophoresis 2005, 26, 1254

112. Wetterhall, M.; Palmblad, M.; Hakansson, P.; Markides, K. E.; Bergquist, J.; J. Proteome Res. 2002, 1, 361.

113. Mikulíková, K.; Eckhardt, A.; Pataridis, S.; Miksík, I.; J. Chromatogr., A 2007, 1155, 125.

114. Weissinger, E. M.; Wittke, S.; Kaiser, T.; Haller, H.; Bartel, S.; Krebs, R.; Golovko, I.; Rupprecht, H. D.; Haubitz, M.; Hecker, H.; Mischak, H.; Fliser, D.; Kidney Int. 2004, 65, 2426.

115. Mischak, H.; Kaiser, T.; Walden, M.; Hillmann, M.; Wittke, S.; Herrmann, A.; Knueppel, S.; Haller, H.; Fliser, D.; Clin. Sci. 2004, 7, 85.

116. Gennaro, L. A.; Vadhanam, M.; Gupta, R. C.; Vouros, P.; Rapid Commun. Mass Spectrom. 2004, 18, 1541.

117. Warnke, U.; Gysler, J.; Hofte, B.; Tjaden, U. R.; Van der Greef, J.; Kloft, C.; Schunack, W.; Jaehde, U.; Electrophoresis 2001, 22, 97.

118. Hernández-Borges, J.; Rodríguez-Delgado, M. Á.; García-Montelongo, F. J.; Cifuentes, A.; J. Sep. Sci. 2005, 28, 948.

119. Juan-Garcia, A.; Font, G.; Pico, Y.; Electrophoresis 2005, 26, 1550.

120. Simo, C.; Barba, S. C.; Cifuentes, A.; Electrophoresis 2005, 26, 1306.

121. Simionato, A. V. C.; Moraes, E. P.; Carrilho, E.; Tavares, M. F. M.; Kenndler, E.; Electrophoresis 2008, 29, 2051.

122. Simionato, A. V. C.; da Silva, D. S.; Lambais, M. R.; Carrilho, E.; J. Mass Spectrom. 2007, 42, 490.

123. Theodorescu, D.; Fliser, D.; Wittke, S.; Mischak, H.; Krebs, R.; Walden, M.; Ross, M.; Eltze, E.; Bettendorf, O.; Wulfing, C.; Semjonow, A.; Electrophoresis 2005, 26, 2797.

124. Hu, A.; Chen, C. T.; Tsai, P. J.; Ho, Y. P.; Anal. Chem. 2006, 78, 5124.

125. Tomlinson, A. J.; Benson, L. M.; Jameson, S.; Johnson, D. H.; Naylor, S.; J. Am. Soc. Mass Spectrom. 1997, 8, 15.

126. Rudaz, S.; Cherkaoui, S.; Dayer, P.; Fanali, S.; Veuthey, J. L.; J. Chromatogr., A 2000, 868, 295.

127. Takahashi, H.; Hayashi, M.; Goto, F.; Sato, S.; Soga, T.; Nishioka, T.; Tomita, M.; Kawai-Yamada, M.; Uchimiya, H.; Ann. Bot. 2006, 98, 819.

128. Sato, S.; Soga, T.; Nishioka, T.; Tomita, M.; Plant J. 2004, 40, 151.

129. Simionato, A. V. C.; Simó, C.; Cifuentes, A.; Lacava, P. T.; Araújo, W. L.; Azevedo, J. L.; Carrilho, E.; Electrophoresis 2006, 27, 2567.

130. McNally, D. J.; Hui, J. P. M.; Aubry, A. J.; Mui, K. K. K.; Guerry, P.; Brisson, J. R.; Logan, S. M.; Soo, E. C.; J. Biol. Chem. 2006, 281, 18489.

131. Lee, R.; Ptolemy, A. S.; Niewczas, L.; Britz-McKibbin, P.; Anal. Chem. 2007, 79, 403 .

132. Saito, N.; Robert, M.; Kitamura, S.; Baran, R.; Soga, T.; Mori, H.; Nishioka, T.; Tomita, M.; J. Proteome Res. 2006, 5, 1979.

133. Harada, K.; Fukusaki, E.; Kobayashi, A.; J. Biosci. Bioeng. 2006, 101, 403.

134. Iio, R.; Chinaka, S.; Tanaka, S.; Takayama, N.; Hayakawa, K.; Analyst 2003, 128, 646.
135. Servais, A. C.; Fillet, M.; Mol, R.; Somsen, G. W.; Chiap, P.; Jong, G. J. D.; Crommen, J.; J. Pharm. Biomed. Anal. 2006, 40, 752.

136. Zhou, L.; Thompson, R.; Reamer, R. A.; Miller, C.; Welch, C.; Ellison, D. K.; Wyvratt, J. M.; J. Chromatogr., A 2003, 987, 409.

137. Toussaint, B.; Palmer, M.; Chiap, P.; Hubert, P.; Crommen, J.; Electrophoresis 2001, 22, 1363.

138. Cherkaoui, S.; Rudaz, S.; Varesio, E.; Veuthey, J. L.; Electrophoresis 2001, 22, 3308 .

139. Kindt, E. K.; Kurzyniec, S.; Wang, S. C.; Kilby, G.; Rossi, D. T.; J. Pharm. Biomed. Anal. 2003, 31, 893.

140. Schultz, C. L.; Moini, M.; Anal. Chem. 2003, 75, 1508.

141. Castro-Puyana, M.; García-Ruiz, C.; Cifuentes, A.; Crego, A. L.; Marina, M. L.; J. Chromatogr., A 2006, 1114, 170.

142. Cherkaoui, S.; Veuthey, J. L.; J. Pharm. Biomed. Anal. 2002, 27, 615.

143. Iwata, Y. T.; Kanamori, T.; Ohmae, Y.; Tsujikawa, K.; Inoue, H.; Kishi, T.; Electrophoresis 2003, 24, 1770.

144. Grard, S.; Morin, Ph.; Dreux, M.; Ribet, J. P.; J. Chromatogr. A 2001, $926,3$.

145. Bonnici, P. J.; Damen, M.; Waterval, J. C. M.; Heck, A. J. R.; Ana.l Biochem. 2001, 290, 292.

146. Srinivasan, K.; Bartlett, M. G.; Rapid Commun. Mass Spectrom. 2000 , 14,624 .

147. Otsuka, K.; Smith, C. J.; Grainger, J.; Barr, J. R.; Patterson Jr., D. G.; Tanaka, N.; Terabe, S.; J.Chromatogr., A 1998, 817, 75.

148. Huhn, C.; Neusüß, C.; Pelzing, M.; Pyell, U.; Mannhardt, J.; Pütz, M.; Electrophoresis 2005, 26, 1389.

149. Tsai, J. L.; Wu, W. S.; Lee, H. H.; Electrophoresis 2000, 21, 1580.

150. Lazar, I. M.; Naisbitt, G.; Lee, M. L.; Chromatographia 1999, 50, 188.

151. Scrano, L.; Bufo, S. A.; Menzinger, F.; Schmitt-Kopplin, P.; Environ. Chem. Lett. 2006, 4, 225.

152. Casiot, C.; Donard, O. F. X.; Potin-Gautier, M.; Spectrochim. Acta, Part B 2002, 57, 173 .

153. Michalke, B.; Schramel, P.; J. Chromatogr., A 1999, 834, 341

154. Choudhary, G.; Chakel, J.; Hancock, W.; Torres-Duarte, A.; McMahon, G.; Wainer, I.; Anal. Chem. 1999, 71, 855.

155. Mauri, P. L.; Basilico, F.; Pietta, P. G.; Pasini, E.; Monti, D.; Sauerwein, W.; J. Chromatogr., B: Anal. Technol. Biomed. Life Sci. 2003, 788, 9.

156. Pitois, A.; De Las Heras, L. A.; Zampolli, A.; Menichetti, L.; Carlos, R.; Lazzerini, G.; Cionini, L.; Salvatori, P. A.; Betti, M.; Anal. Bioanal. Chem. 2006, 384, 751 .

157. Peterson, Z. D.; Lee, M. L.; Graves, S. W.; J. Chromatogr., B: Anal. Technol. Biomed. Life Sci. 2004, 810, 101.

158. Polec-Pawlak, K.; Abramski, J. K.; Semenova, O.; Hartinger, C. G.; Timerbaev, A. R.; Keppler, B. K.; Jarosz, M.; Electrophoresis 2006, 27, 1128 . 


\section{ELETROFORESE CAPILAR ACOPLADA À ESPECTROMETRIA DE MASSAS (CE-MS): VINTE ANOS DE DESENVOLVIMENTO}

Nilson Antonio Assunção e Etelvino José Henriques Bechara

Departamento de Bioquímica, Instituto de Química, Universidade de São Paulo, CP 26077, 05513-970 São Paulo - SP, Brasil Ana Valéria Colnaghi Simionato*\# e Marina Franco Maggi Tavares

Departamento de Química Fundamental, Instituto de Química, Universidade de São Paulo, CP 26077, 05513-970 São Paulo - SP, Brasil

Emanuel Carrilho

Departamento de Química e Física Molecular, Instituto de Química de São Carlos, Universidade de São Paulo, CP 780, 13560-970 São Carlos - SP, Brasil

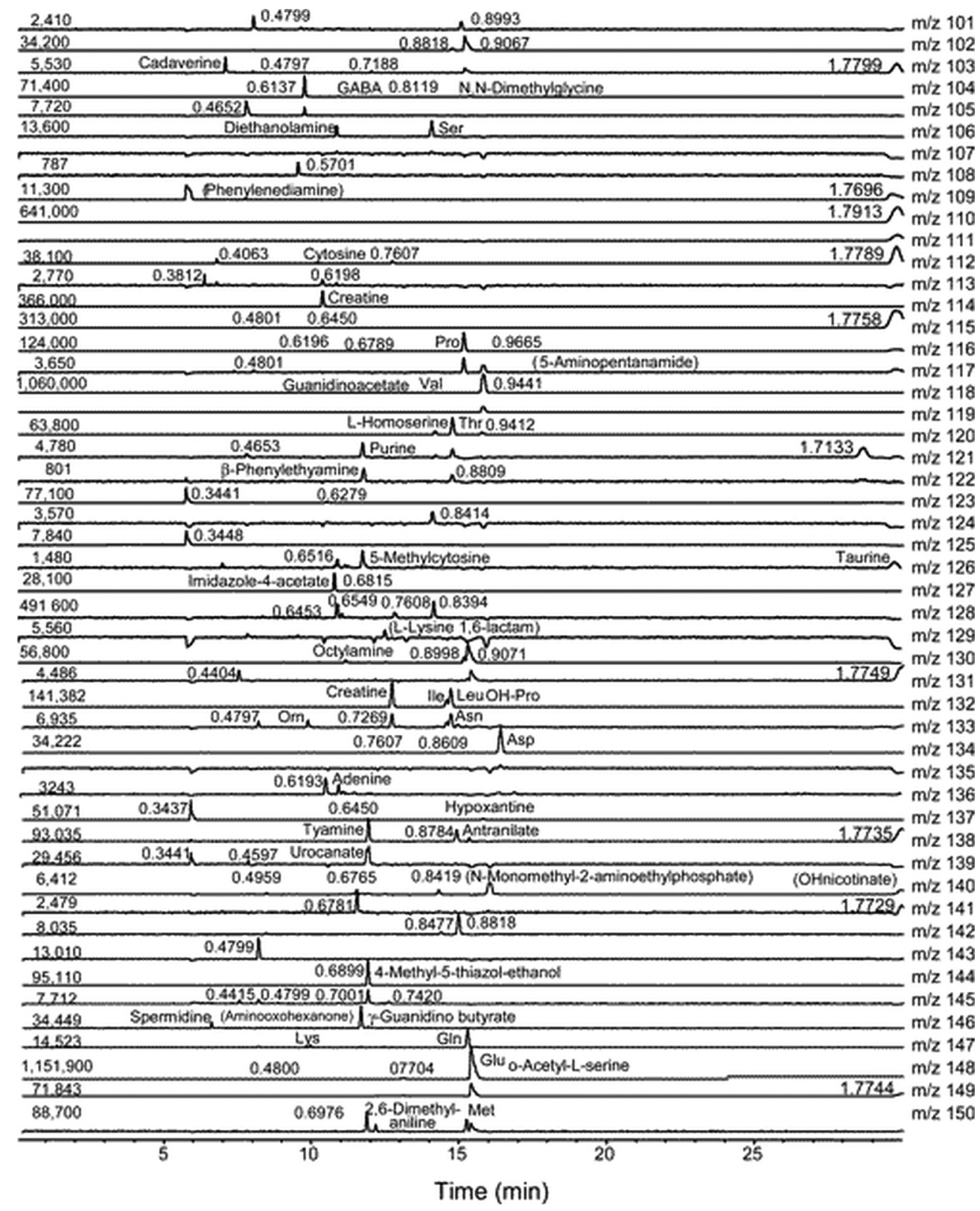

Figura 1S. Eletroferogramas dos íons extraídos (EIEs) de metabólitos catiônicos de B. subtillis. Os números à esquerda representam as abundâncias de cada pico, associadas ao pico base; os números sobre os picos representam os tempos de migração. Reproduzida da ref. 91 com permissão da ACS

*e-mail: avsimionato@iqm.unicamp.br

"Endereço atual: Departamento de Química Analítica, Instituto de Química,

Universidade de Campinas, CP 6154, 13083-970 Campinas - SP, Brasil 